\title{
Determinants of Health-Promoting Behaviors among Type 2 Diabetic Patients: Voice of Iran
}

\author{
Azar Tol', Bahram Mohebbi², Roya Sadeghi' ${ }^{*}$, Agh Babak Maheri1, \\ Mohammad Reza Eshraghian ${ }^{3}$ \\ ${ }^{1}$ Department of Health Education and Promotion, School of Public Health, Tehran University of Medical \\ Sciences, Tehran, Iran \\ ${ }^{2}$ School of Medicine, Iran University of Medical Sciences, Tehran, Iran \\ ${ }^{3}$ Department of Biostatistics, School of Public Health, Tehran University of Medical Sciences, Tehran, Iran \\ Email: ${ }^{\text {Sadeghir@tums.ac.ir }}$
}

Received 19 August 2014; revised 30 August 2014; accepted 10 September 2014

Copyright (C) 2014 by authors and Scientific Research Publishing Inc.

This work is licensed under the Creative Commons Attribution International License (CC BY). http://creativecommons.org/licenses/by/4.0/

(c) (i) Open Access

\begin{abstract}
Introduction: The aim of this study was to determine Health-Promoting Behaviors among type 2 diabetic mellitus patients. Patients and Methods: A cross-sectional study was conducted on 440 diabetic patients referred to selected teaching hospitals affiliated to Tehran University of Medical Sciences (TUMS) during six months in 2013. A two section 40-items self-report Questionnaire with demographic variables (12 items) and Health-Promoting Behaviors scale (28 items) included exercise ( 7 items), risk reducing ( 7 items), life enjoyment ( 3 items), stress management (5 items), responsibility (3 items) and healthy eating (3 items) domains. Data was analyzed using SPSS software version 11.5. Level of significance was set at $p<0.05$ level. Results: Mean scores of total health promoting behaviors in participants were $(55.88 \pm 18.09)$ and in domains of exercise, risk reducing, life enjoyment, stress management, responsibility and healthy eating were (8.2 \pm 6.5$)$, (12.2 \pm 6.1$),(7.8 \pm 2.6),(12.3 \pm 3.8),(3.3 \pm 3.1)$ and $(6.9 \pm 2.8)$ respectively. Life enjoyment was emphasized as the most significant domain in health promoting behaviors scale (65 percent). Study results revealed that there was a significant association among total health promoting behavior and age $(p=0.01)$, occupation $(p=0.01)$, family income $(p<0.001)$, BMI $(p=0.01)$ and $\mathrm{HbA}_{1} \mathrm{C}(p<0.001)$. Conclusion: Study findings revealed the necessity of tailoring specific intervention programs to promote exercise and responsibility domains posit.
\end{abstract}

\section{Keywords}

Health-Promoting Behaviors, Type 2 Diabetes, Patients

\footnotetext{
${ }^{*}$ Corresponding author.
}

How to cite this paper: Tol, A., et al. (2014) Determinants of Health-Promoting Behaviors among Type 2 Diabetic Patients: Voice of Iran. Open Journal of Endocrine and Metabolic Diseases, 4, 219-224. 


\section{Introduction}

Diabetes type 2 is a common chronic condition nearly in the world [1]-[3]. It is highly prevalent in developing countries [2] [3] including Iran [4] [5] which estimated about 2\% - 10\% prevalence in 2008 [6] [7]. Regarding epidemiologic transition with rapid changes of dietary habits and tendency to high calorie food with low nutritional value, physical inactivity, and smoking non-communicable disease prevalence are increasing in which one of the most of them is type 2 diabetes [8]. Lifestyle and human behaviors are responsible for majority of noncommunicable disease [9]. Approximately 53\% of death causes are related to Lifestyle and human behaviors [1] $[2]$.

The nature of diabetes type 2 and its biopsychosocial determinants of onset, progress and complications [8] [9] highlighted the importance of addressing Diabetes Health-Promoting Behaviors (DHPB). Health promoting behaviors are one of the most effective ways for personal health control and maintenance [10]. Some daily behaviors, social and psychosocial factors are challenges to adhere treatment regimen as a barrier for self-care adaptation [11]-[13]. Sloan et al. (2004) indicated self-care behaviours adherence decreased hospitalization rate among patients with type 2 diabetes [14]. Studies concluded adopting healthy lifestyle in pattern of self-care would be effective to diabetes control [15]. Implementation multidisciplinary interventions and intersectoral participation are recommended to overcome self-care barriers [11] [12]. Since the importance of Health-Promoting Behaviors adherence and necessity of understanding influential factors among type 2 diabetic patients, this study aimed at determining Health-Promoting Behaviors among type 2 diabetic patients.

\section{Patients and Methods}

A cross-sectional study was performed for a period of six months in 2013. The participants were selected by continuous sampling of patients with type 2 diabetes referred to four selected teaching hospitals affiliated to Tehran University of Medical Sciences (TUMS) in Tehran, Iran. The inclusion criteria were diabetes confirmation by endocrinologists and patients who agreed to sign a written informed consent to study participation. Confirmed psychological conditions, gestational diabetes and lack of interest to participate were exclusion criteria in the study. In this research signed up 440 patients on the basis of a $p$ ratio between diabetic patients $(0.7 \%)$ at 95\% confidence level and $80 \%$ power test, considering 25\% sample size reduction.

A two section 40-items self-report Questionnaire with demographic variables (12 items) and Health-Promoting Behaviors scale (28 items) including exercise (7 items), risk reducing ( 7 items), life enjoyment (3 items), stress management (5 items), responsibility ( 3 items) and healthy eating ( 3 items) domains. The responses to each item in domains were rated between 0 and 4 on a measurement scale based on a Likert scale [0: Never, 1: Rarely, 2: Occasionally, 3: Usually, 4: Always]. Therefore, in each of domains, higher scores meant better Health-Promoting Behaviors.

Since the lack of specific instrument about health promoting behaviors for patients with type 2 diabetes, in Iranian literature, we found an article about this important subject [10]. Therefore, instrument was translated from English to Persian and vice versa. This process was done by two expert teams of endocrinologists and Health Education and Promotion professionals. The final version of instrument was extracted after comparing primary versions. The final version obtained validity and reliability after following process. Content validity method was performed by ten members of academic board of TUMS, who were experts on diabetes and health education and promotion fields. Internal reliability of the original scale and its subscales showed adequate agreement $(\alpha=0.90)$. To determine internal reliability in this study, a test-retest method was performed. The final version of instrument filled out twice in two weeks interval. Chronbach's alpha was 0.89. The internal reliabilities of domains were between 0.65 and 0.90 . The results of the pilot study were not contained in the main study. Regarding ethical consideration, permission was achieved from TUMS Research Ethical Committee, all patients were informed about study objectives in detail by skilled interviewer and they filled written informed consent. Data was analyzed by using SPSS software version 11.5 through descriptive [mean and (SD)] and inference $\left[x^{2}\right.$, independent t-test, ANOVA] statistical tests. According to histogram and normalization of data, parametric tests were used. Results were considered significant at the conventional $p<0.05$ level.

\section{Results}

Four hundred forty were participated in the study. Demographic and health related variables of participants were 
demonstrated in Table 1. Mean scores of total health promoting behaviors in participants were $(55.88 \pm 18.09)$ and in domains of exercise, risk reducing, life enjoyment, stress management , responsibility and healthy eating were (8.2 \pm 6.5$),(12.2 \pm 6.1)$, (7.8 \pm 2.6$),(12.3 \pm 3.8),(3.3 \pm 3.1)$ and $(6.9 \pm 2.8)$ respectively. Life enjoyment was emphasized as the most significant domain in health promoting behaviors scale (65 percent). It notes that study participants achieved 49.8 percent of total health promoting behavior score. Table 2 presents mean score and standard deviation of health promoting behavior dimensions of participants. Patients with age less than 50 years old received higher mean scores of others. Physical activity was the only domains which had significant association with gender as male $(p=0.02)$. Patients with more than 10 years disease duration and Insulin therapy had significant association with responsibility and healthy eating. Mean scores of civil servant in some domain were higher than other occupation groups. Higher education and good family income revealed significant association with some HPB domains. Obese, smokers and poor diabetes patients received lee mean scores of majority HPB domains. Table 3 represented relation between mean scores in health promoting behavior domains based on socio demographic and health related variables in details among study participants.

Table 1. Demographic and health related variables of participants.

\begin{tabular}{|c|c|c|c|}
\hline Variable & Number/Percent & Variable & Number/Percent \\
\hline Gender & & Marital status & \\
\hline Male & $170(38.6 \%)$ & Single & $12(2.7 \%)$ \\
\hline Female & $270(61.4 \%)$ & Married & $428(97.3 \%)$ \\
\hline Age Groups (yrs) & & $B M I$ & \\
\hline$<50$ & 118 (26.8\%) & $<25$ & $122(27.7 \%)$ \\
\hline $50-65$ & 219 (49.8\%) & $25-30$ & $186(42.3 \%)$ \\
\hline$>65$ & $103(23.4 \%)$ & $>30$ & $132(30 \%)$ \\
\hline Educational Levels & & Type of Occupation & \\
\hline Illiterate & $144(23.7 \%)$ & Housewife & $243(55.2 \%)$ \\
\hline Primary & 178 (40.5\%) & Civil Servant & $33(7.5 \%)$ \\
\hline Secondary \& Diploma & $73(16.6 \%)$ & Non-Civil Servant & $91(20.7 \%)$ \\
\hline \multirow[t]{2}{*}{ Higher than Diploma } & 45 (10.2\%) & Retired & $56(12.7 \%)$ \\
\hline & & Unemployed & $17(3.9 \%)$ \\
\hline Disease Duration (yrs) & & Family Income & \\
\hline$<3$ & $125(28.4)$ & Low & $101(23 \%)$ \\
\hline $3-10$ & 202 (45.9) & Moderate & $252(57.3 \%)$ \\
\hline$>10$ & 113 (25.7) & Good & 87(19.7\%) \\
\hline Type of Treatment & & History of Diabetes & \\
\hline Oral Agents & $274(62.3 \%)$ & Yes & $311(70.7)$ \\
\hline Insulin & 91 (20.7\%) & NO & 129 (29.3) \\
\hline Both & $75(17 \%)$ & & \\
\hline$H b A_{1} c(\%)$ & & Smoking & \\
\hline$<7$ & 139 (31.6\%) & Yes & $65(14.8)$ \\
\hline $7-8.5$ & $126(28.6 \%)$ & NO & $375(85.2)$ \\
\hline$>8.5$ & 175 (39.8\%) & & \\
\hline
\end{tabular}


Table 2. Mean score and standard deviation of health promoting behavior dimensions of participants.

\begin{tabular}{cccc}
\hline Dimensions & Mean \pm SD & Score Range & Percent \\
\hline Exercise & $8.2 \pm 6.5$ & $0-28$ & 30 \\
Risk Reducing & $12.2 \pm 6.1$ & $0-28$ & 43.5 \\
Life Enjoyment & $7.8 \pm 2.6$ & $0-12$ & 65 \\
Stress Management & $12.3 \pm 3.8$ & $0-20$ & 61.5 \\
Responsibility & $3.3 \pm 3.1$ & $0-12$ & 27.5 \\
Healthy Eating & $6.9 \pm 2.8$ & $0-12$ & 57.5 \\
Total HPB & $55.88 \pm 18.09$ & $0-112$ & 49.8 \\
\hline
\end{tabular}

Table 3. Relation between mean scores in health promoting behavior domains based on socio demographic and health related variables among study participants.

\begin{tabular}{|c|c|c|c|c|c|c|c|}
\hline Variables & Exercise & Risk Reducing & Life Enjoyment Stress & Sanagement & Responsibility & Healthy Eating & Total HPB \\
\hline Age group & 0.02 & $<0.001$ & $<0.001$ & $<0.001$ & NS & NS & $<0.001$ \\
\hline Gender & 0.02 & NS & NS & NS & NS & NS & NS \\
\hline Disease Duration & NS & NS & NS & NS & $<0.001$ & 0.008 & NS \\
\hline Level of Education & $<0.001$ & $<0.001$ & $<0.001$ & $<0.001$ & 0.06 & 0.002 & $<0.001$ \\
\hline Occupation & 0.03 & 0.01 & 0.03 & 0.002 & NS & NS & $<0.001$ \\
\hline Family Income & 0.005 & 0.01 & $<0.001$ & $<0.001$ & 0.01 & 0.07 & $<0.001$ \\
\hline BMI & 0.01 & 0.02 & 0.01 & NS & NS & NS & 0.01 \\
\hline Type of Treatment & NS & NS & NS & NS & $<0.001$ & $<0.001$ & NS \\
\hline $\mathrm{HbA}_{1} \mathrm{C}$ & NS & 0.05 & 0.06 & 0.01 & $<0.001$ & $<0.001$ & $<0.001$ \\
\hline Smoking & 0.01 & 0.03 & 0.01 & 0.06 & $<0.001$ & $<0.001$ & $<0.001$ \\
\hline
\end{tabular}

NS: Not Significant; BMI: Body Mass Index.

\section{Discussion}

The aim of this study was to determine Health-Promoting Behaviors among type 2 diabetic mellitus patients. Study results presented physical activity domain had significant association with age less than 50 years old, being male, better socioeconomic status (SES) and BMI less than 30. This result is in the line of Norouzi et al. study (2010) which conducted determinants of regular physical activity in women referee to Karaj Diabetes institute [16]. However, Wu et al. (2004) indicated that diabetes patients were more to engage in health-promoting behaviors if they were physically well, but their study results showed that demographic and illness variables were unrelated to health practices [17]. The differences age of participants in two studies might be justify the variety of results. McDonald et al. (2002) study represented the level of education had association with healthpromoting behaviors [18]. Nothwehr et al. (2000) indicated that $66 \%$ of diabetic patients engaged in some physical activity [19].

Study results indicated that civil servant, education more than diploma, better income, BMI less than 30 and non smoker participants were less in risk reduction and more life enjoyment domains. It seems that better physical fitness, life expectancy, job security, and better social class because of income satiability higher education. Chen et al. (2013) represented that participants younger than 50 years reported a higher score in risk reducing behaviors than the other age groups [10]. In the stress management domain, those younger than 50 years, civil servant, education more than diploma, better income, $\mathrm{HbA}_{1} \mathrm{C}$ less than 8.5 (poor diabetic control) and non smoker participants had better performance in the named domain. Yi et al. (2008) results suggested that higher levels 
of anger coping might promote poorer diabetes control in diabetes patients. This result confirmed our study findings [20]. In the health responsibility dimension revealed higher score of disease duration more than 10 years, moderate and better income, Insulin therapy, $\mathrm{HbA}_{1} \mathrm{c}$ less than 8.5 (better diabetic control) and non smoker participant. It might be because of more diabetes duration time had a positive impact in using appropriate coping strategies and dealing with disease [21]. On the other hand, participants with high income and good economic position might have better nutrition behaviors and also good adherence to treatment regimen in type 2 diabetes [5]. In several studies confirmed that desirable adherence of diabetes treatment can resulted good diabetes control [22].

Study results revealed that mean score of healthy eating domain was higher in participants with education more than diploma, $\mathrm{HbA}_{1} \mathrm{C}$ less than 8.5 and non smokers. Tol et al. (2014) suggested family concern about healthy dietary habits among type 2 diabetic patients is very influential [5]. It seems that the more educated family, the more adopting healthy diet which can be resulted in better diabetes control. Also, Mangou et al. (2012) confirmed the association between adequate diet quality and desirable diabetes control [23]. Marcy et al. (2011) reported that presenting diet barriers in the study population which had borderline $\mathrm{HbA}_{1} \mathrm{C}$ in developing country in their qualitative study [24]. This result confirmed that decreasing nutrition diabetes barriers can promote diabetes control. Participants less than 50 years old, civil servant, education more than diploma moderate and good income, BMI less than 30, $\mathrm{HbA}_{1} \mathrm{C}$ less than 8.5 and non-smoking participants had higher total HPB in diabetes scores. In this line, Wang et al. (2008) highlighted educational level as an influential factor on adoption HPB in patients with diabetes [25]. In sum up studies showed HPB in patients with diabetes is effective in promoting diabetes control [26] [27].

This study had some limitations as followed: 1) patients' HPB instrument was a self-report questionnaire and it is possible that the results might not have contributed to accurate estimation, and 2) a few available researches in the literature had used HPB instrument, therefore it was a limitation for comparing the results and previous studies.

\section{Conclusion}

Study findings highlighted that SES and clinical characteristics and adopting some behaviors like smoking had influential role in adopting HPB in patients with diabetes. Being relatively low obtained scores (up to mean) of all HPB domains, it seems to need specific attention to promote all dimensions especially the lowest ones such as exercise and responsibility to maintain health using educational interventional programs.

\section{Acknowledgements}

The authors appreciate all the study patients who participated in the study and all other individuals who contributed to the successful accomplishment of this research. This study supported by research chancellor of Tehran University of Medical Sciences (Grant Number: 22842). The authors declare there is no conflict of interest.

\section{References}

[1] Center for Disease Control and Prevention (2005) National Diabetes Fact Sheet. Last Accessed on 2005 November 1. http://www.cdc.gov

[2] Spinaci, S., Currat, L., Shetty, P., Crowell, V. and Kehler, J. (2006) Tough Choices: Investing in Health for Development: Experiences from National Follow-Up to Commission on Macroeconomics and Health. WHO Report.

[3] Whiting, D.R., Guariguata, L., Weil, C. and Shaw, J. (2011) IDF Diabetes Atlas: Global Estimates Diabetes for 2011 and 2030. Diabetes Research and Clinical Practice, 94, 311-321. http://dx.doi.org/10.1016/j.diabres.2011.10.029

[4] Mohebi, S., Azadbakht, L., Feizi, A., Sharifirad, G. and Kargar, M. (2013) Structural Role of Perceived Benefits and Barriers to Self-Care in Patients with Diabetes. Journal of Education and Health Promotion, 2, 37. http://dx.doi.org/10.4103/2277-9531.115831

[5] Tol, A., Mohebbi, B. and Sadeghi, R. (2014) Evaluation of Dietary Habits and Related Factors among Type 2 Diabetic Patients: An Innovative Study in Iran. Journal of Education and Health Promotion, 21, 4.

[6] Esteghamati, A., Gouya, M.M., Abbasi, M., Delavary, A., Alikhani, S., Alaedini, F., et al. (2008) Prevalence of Diabetes Mellitus and Impaired Fasting Glucose in the Adult Population of Iran: The National Survey of Risk Factors for Non-Communicable Disease of Iran. Diabetes Care, 31, 96-98. http://dx.doi.org/10.2337/dc07-0959

[7] Azizi, F., Hatemi, H. and Janghorbani, M. (2000) Epidemiology and Communicable Disease Control in Iran. Tehran 
Eshtiagh Publication, Iran, 34-39.

[8] Baghbanian, A. and Tol, A. (2012) The Introduction of Self-Management in Type 2 Diabetes Care: A Narrative Review. Journal of Education and Health Promotion, 1, 35. http://dx.doi.org/10.4103/2277-9531.102048

[9] Knowler, W.C., Barrett-Connor, E., Fowler, S.E., Hamman, R.F., Lanchin, J.M., Walker, E.A., et al. (2002) Reduction in the Incidence of Type 2 Diabetes with Lifestyle Intervention or Metformin. The New England Journal of Medicine, 346, 393-403. http://dx.doi.org/10.1056/NEJMoa012512

[10] Chen, C.P., Peng, Y.S.H., Weng, H.H., Yen, H.H. and Chen, M.Y. (2013) Health-Promoting Behaviour Is Positively Associated with Diabetic Control among Type 2 Diabetes Patients. Open Journal of Nursing, 3, 274-280. http://dx.doi.org/10.4236/ojn.2013.32037

[11] Vermeire, E., Wens, J., Van Royen, P., Biot, Y., Hearnshaw, H. and Lindenmeyer, A. (2005) Interventions for Improving Adherence to Treatment Recommendations in People with Type 2 Diabetes Mellitus. The Cochrane Database of Systematic Reviews, No. 1, CD003638.

[12] Vermeire, E., Hearnshaw, H., Van Royen, P. and Denekens, J. (2001) Patient Adherence to Treatment: Three Decades of Research. A Comprehensive Review. Journal of Clinical Pharmacy and Therapeutics, 26, 331-342. http://dx.doi.org/10.1046/j.1365-2710.2001.00363.x

[13] Tol, A., Majlessi, F., Rahimi Foroshani, A., Mohebbi, B., Shojaeezadeh, D. and Salehi Node, A. (2012) Cognitive Adaptation among Type II Diabetic Patients Referring to Tehran University of Medical Sciences Hospitals in Adherence to Treatment. Health System Research, 8, 1068-1077.

[14] Sloan, F.A., Bethel, M.A., Lee, P.P., Brown, D.S. and Feinglos, M.N. (2004) Adherence to Guidelines and Its Effects on Hospitalizations with Complications of Type 2 Diabetes. The Review of Diabetic Studies, 1, 29-38. http://dx.doi.org/10.1900/RDS.2004.1.29

[15] American Diabetes Association (2014) Standards of Medical Care in Diabetesd-2014. Diabetes Care, 37, S14-S80.

[16] Norouzi, A., Ghofranipour, F., Heydarnia, A. and Tahmasebi, R. (2010) Determinants of Physical Activity Based on Health Promotion Model (HPM) in Diabetic Women of Karaj Diabetic Institute. Iranian South Medical Journal, 13, 41-51.

[17] Wu, A.M., Tang, C.S. and Kwok, T.C. (2004) Physical and Psychosocial Factors Associated with Health-Promoting Behaviors among Elderly Chinese with Type-2 Diabetes. Journal of Health Psychology, 9, 731-740. http://dx.doi.org/10.1177/1359105304045371

[18] McDonald, P.E., Wykle, M.L., Misra, R., Suwonnaroop, N. and Burant, C.J. (2002) Predictors of Social Support, Acceptance, Health-Promoting Behaviors, and Glycemic Control in African-Americans with Type 2 Diabetes. Journal of National Black Nurses' Association, 13, 23-30.

[19] Nothwehr, F. and Stump, T. (2000) Health-Promoting Behaviors among Adults with Type 2 Diabetes: Findings from the Health and Retirement Study. Preventive Medicine, 30, 407-414. http://dx.doi.org/10.1006/pmed.2000.0658

[20] Yi, J.P., Yi, J.C., Vitaliano, P.P. and Weinger, K. (2008) How Does Anger Coping Style Affect Glycemic Control in Diabetes Patients? International Journal of Behavioral Medicine, 15, 167-172. http://dx.doi.org/10.1080/10705500802219481

[21] Tol, A., Mohebbi, B., Hossaini, M. and Majless, F. (2014) Developing a Valid and Reliable Coping Self-Efficacy Scale (CSES) among Patients with Type 2 Diabetes: Iranian Version. Open Journal of Endocrine and Metabolic Diseases, 4, 45-51. http://dx.doi.org/10.4236/ojemd.2014.43005

[22] Midhet, F.M., Al-Mohaimeed, A.A. and Sharaf, F.K. (2010) Lifestyle Related Risk Factors of Type 2 Diabetes Mellitus in Saudi Arabia. Saudi Medical Journal, 31, 768-774.

[23] Mangou, A., Grammatikopoulou, M.G., Mirkopoulou, D., Sailer, N., Kotzamanidis, C. and Tsigga, M. (2012) Associations between Diet Quality, Health Status and Diabetic Complications in Patients with Type 2 Diabetes and Comorbid Obesity. Endocrinología y Nutrición, 59, 109-116. http://dx.doi.org/10.1016/j.endonu.2011.10.003

[24] Marcy, T.R., Britton, M.L. and Harrison, D. (2011) Identification of Barriers to Appropriate Dietary Behavior in Low-Income Patients with Type 2 Diabetes Mellitus. Diabetes Therapy, 2, 9-19. http://dx.doi.org/10.1007/s13300-010-0012-6

[25] Wang, H.F., Tang, W.R. and Liu, H.E. (2008) Related Factors of Diabetes Mellitus Disease Features and Quality of Life: The Report of a Regional Teaching Hospital in Central Taiwan. Endocrinology \& Diabetology, 21, 1-15.

[26] Irwin, M.L., Mayer-Davis, E.J., Addy, C.L., Pate, R.R., Durstine, J.L., Stolarczyk, L.M. and Ainsworth, B.E. (2000) Moderate-Intensity Physical Activity and Fasting Insulin Levels in Women: The Cross-Cultural Activity Participation Study. Diabetes Care, 23, 449-454. http://dx.doi.org/10.2337/diacare.23.4.449

[27] Jones, H., Edwards, L. and Vallis, T.M. (2003) Changes in Diabetes Self-Care Behaviors Make a Difference in Glycemic Control: The Diabetes Stages of Change Study. Diabetes Care, 26, 732-737. http://dx.doi.org/10.2337/diacare.26.3.732 
Scientific Research Publishing (SCIRP) is one of the largest Open Access journal publishers. It is currently publishing more than 200 open access, online, peer-reviewed journals covering a wide range of academic disciplines. SCIRP serves the worldwide academic communities and contributes to the progress and application of science with its publication.

Other selected journals from SCIRP are listed as below. Submit your manuscript to us via either submit@scirp.org or Online Submission Portal.
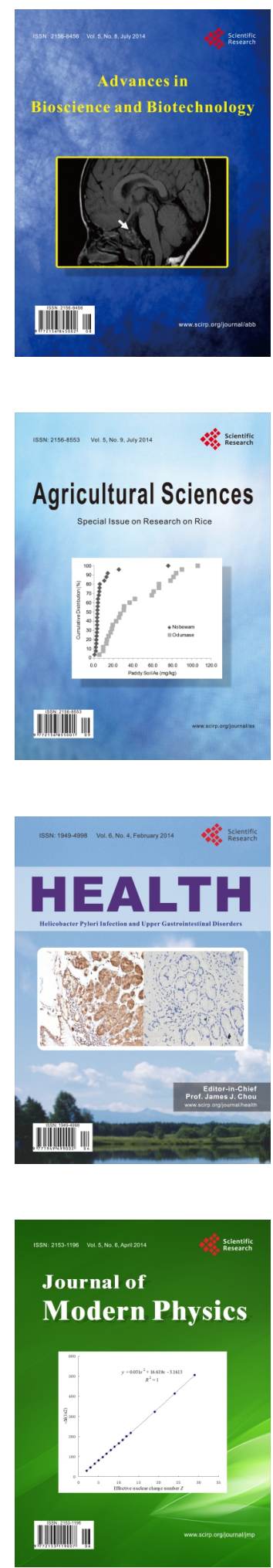
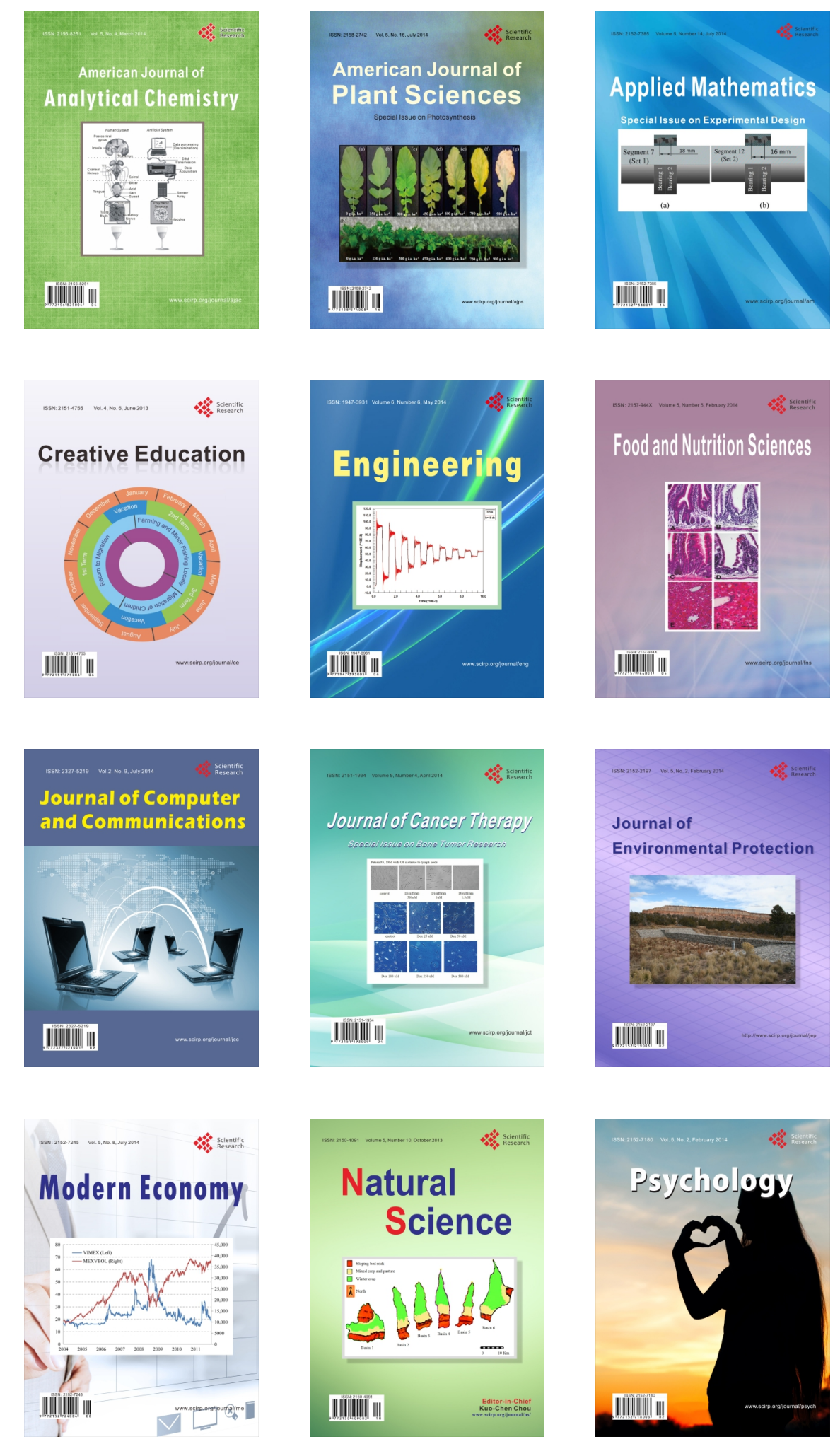